\title{
Administration of Thuya occidentalis in homeopathic dilution in goats vaccinated against bluetongue virus: a preliminary study
}

\author{
A. Grossi, N. Lacetera ${ }^{1}$ and B. Ronchi \\ Dipartimento di Produzioni Animali, Università degli Studi della Tuscia, Viterbo, Italy
}

\begin{abstract}
This preliminary study was realized to assess the effects of Thuya occidentalis in homeopathic dilution (200 centesimal dilution) on nonspecific lymphoblastogenesis of goats vaccinated against bluetongue virus serotype 2 (BTV). Twenty Saanen goats were treated as follows: six goats were vaccinated with a live attenuated vaccine against BTV, four goats were vaccinated and injected with $1 \mathrm{ml}$ of an alcoholic solution containing Thuya occidentalis, six goats were neither vaccinated nor given thuya, the remaining four goats were not vaccinated, but treated with thuya. Administration of thuya prevented depression of nonspecific lymphoblastogenesis, which followed vaccination.
\end{abstract}

KEY WORDS: goats, Thuya occidentalis, vaccination, bluetongue, lymphoblastogenesis

\section{INTRODUCTION}

We have recently reported that vaccination of goats with a live attenuated vaccine against bluetongue virus serotype 2 (BTV) is responsible for a profound depression of nonspecific lymphoblastogenesis (Lacetera and Ronchi, in press). According to previous studies, homeopathic medications might be of help in alleviating the immune depression that may follow vaccinations or other stressors (Schuberth et al., 2002; Teixeira, 2002).

The present preliminary study was carried out in the course of the study of Lacetera and Ronchi (in press), and was aimed to assess nonspecific lymphoblastogenesis in goats vaccinated against BTV, and treated with Thuya occidentalis in homeopathic dilution at the time of vaccination.

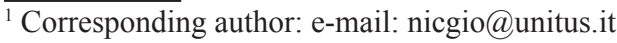




\section{MATERIAL AND METHODS}

Twenty non-pregnant and non-lactating Saanen goats of about 12 months of age were utilized for the study. Six goats were vaccinated (Va) with a monovalent live attenuated vaccine serotype 2 against BTV (Onderstepoort Biological Products Ltd., South Africa); four goats were also vaccinated, and at the time of vaccination injected subcutaneously with $1 \mathrm{ml}$ of an alcoholic solution of Thuya occidentalis in a homeopathic dilution (200 centesimal) (Omeonatus, Arezzo, Italy) (VaT); six goats were neither vaccinated nor given thuya (NVa); four goats were not vaccinated, but received the same amount of thuya of VaT goats (NVaT).

As already described elsewhere (Lacetera and Ronchi, in press), fourteen and seven days before, and seven, 21 and 49 days after vaccination, nonspecific lymphoblastogenesis was evaluated by measuring the DNA synthesis (Biotrak, APB, Milano, Italy) in peripheral blood mononuclear cells (PBMCs) stimulated with phytohemagglutinin, concanavalin-A and pokeweed mitogen.

The same days of lymphoblastogenesis evaluations, blood samples were taken to determine serum concentrations of anti-BTV antibodies. The presence of anti-BTV antibodies in the serum was established by a competitive ELISA using a commercial kit (Bluetongue Virus Antibody Test Kit, cELISA, VMRD, Pullman, WA). Results were expressed as mean of inhibition percentage (IP): IP $=100-\left(\mathrm{OD}_{620 \mathrm{~nm}}\right.$ sample $/ \mathrm{OD}_{620 \mathrm{~mm}}$ negative control $) \times 100$, and as indicated by the manufacturer, an IP of $50 \%$ was considered as the positive threshold.

Rectal temperatures of goats were measured twice per week.

\section{Statistical analysis}

Data of DNA synthesis were analysed by using a repeated measures procedure (Instat, GraphPad Software Inc., USA). Values are expressed as Lsmeans \pm SEM, and effects were considered to be significant at $\mathrm{P}<0.05$.

\section{RESULTS}

No significant reactions were observed at the injection sites, and no clinical signs of BTV or other diseases were observed during the experiment. Rectal temperatures did not change during the experiment, and values did not differ between goats belonging to the four groups (not shown).

As already described (Lacetera and Ronchi, in press), PBMCs from Va goats exhibited a lower response to mitogens after vaccination (Table 1).

Contrarily, PBMCs isolated from VaT goats did not change their response to mitogens after vaccination. Analogously, PBMCs isolated from $\mathrm{NVa}$ or NVaT goats did not modify their responsiveness to mitogens during the entire experiment. 
Table 1. Least square means \pm SEM of DNA synthesis (optical density) in peripheral blood mononuclear cells of goats vaccinated (Va), vaccinated and treated with thuya (VaT), not vaccinated $(\mathrm{NVa})$, and not vaccinated and treated with thuya (NVaT)

\begin{tabular}{|c|c|c|c|}
\hline \multirow{2}{*}{$\begin{array}{l}\text { Groups and days } \\
\text { from vaccination }\end{array}$} & \multicolumn{3}{|c|}{ Mitogens $^{1}$} \\
\hline & PHA & ConA & PWM \\
\hline \multicolumn{4}{|l|}{$\overline{V a}$} \\
\hline-14 & $2.59 \pm 0.25^{b}$ & $2.94 \pm 0.2^{\mathrm{b}}$ & $1.80 \pm 0.3^{b}$ \\
\hline-7 & $2.16 \pm 0.43^{b}$ & $2.94 \pm 0.21^{\mathrm{b}}$ & $1.78 \pm 0.38^{b}$ \\
\hline 0 & $2.51 \pm 0.19^{b}$ & $3.03 \pm 0.18^{b}$ & $1.69 \pm 0.18^{b}$ \\
\hline+7 & $1.09 \pm 0.25^{\mathrm{a}}$ & $1.68 \pm 0.34^{\mathrm{a}}$ & $0.66 \pm 0.13^{\mathrm{a}}$ \\
\hline+21 & $0.76 \pm 0.16^{\mathrm{a}}$ & $0.94 \pm 0.13^{\mathrm{a}}$ & $0.46 \pm 0.09^{\mathrm{a}}$ \\
\hline+49 & $1.19 \pm 0.21^{\mathrm{a}}$ & $1.36 \pm 0.19^{\mathrm{a}}$ & $0.47 \pm 0.1^{\mathrm{a}}$ \\
\hline \multicolumn{4}{|l|}{$\operatorname{VaT}$} \\
\hline-14 & $1.95 \pm 0.25$ & $2.42 \pm 0.42$ & $1.16 \pm 0.15$ \\
\hline-7 & $2.05 \pm 0.33$ & $2.72 \pm 0.45$ & $1.56 \pm 0.19$ \\
\hline 0 & $1.66 \pm 0.18$ & $2.19 \pm 0.32$ & $1.22 \pm 0.12$ \\
\hline+7 & $1.82 \pm 0.13$ & $2.54 \pm 0.33$ & $1.39 \pm 0.12$ \\
\hline+21 & $1.87 \pm 0.09$ & $2.16 \pm 0.19$ & $1.57 \pm 0.24$ \\
\hline+49 & $1.85 \pm 0.11$ & $2.33 \pm 0.22$ & $1.41 \pm 0.21$ \\
\hline \multicolumn{4}{|l|}{$N V a$} \\
\hline-14 & $1.93 \pm 0.5$ & $2.32 \pm 0.47$ & $1.31 \pm 0.48$ \\
\hline-7 & $2.01 \pm 0.43$ & $2.33 \pm 0.47$ & $1.37 \pm 0.28$ \\
\hline 0 & $1.99 \pm 0.43$ & $2.11 \pm 0.51$ & $1.22 \pm 0.33$ \\
\hline+7 & $2.20 \pm 0.35$ & $2.18 \pm 0.32$ & $1.27 \pm 0.24$ \\
\hline+21 & $2.15 \pm 0.5$ & $2.17 \pm 0.39$ & $1.31 \pm 0.41$ \\
\hline+49 & $2.36 \pm 0.47$ & $2.21 \pm 0.40$ & $1.25 \pm 0.36$ \\
\hline \multicolumn{4}{|l|}{ NVaT } \\
\hline-14 & $1.93 \pm 0.5$ & $2.18 \pm 0.47$ & $1.40 \pm 0.40$ \\
\hline-7 & $2.06 \pm 0.41$ & $2.31 \pm 0.47$ & $1.21 \pm 0.2$ \\
\hline 0 & $1.92 \pm 0.35$ & $1.99 \pm 0.51$ & $1.11 \pm 0.39$ \\
\hline+7 & $2.01 \pm 0.31$ & $2.01 \pm 0.32$ & $1.45 \pm 0.43$ \\
\hline+21 & $2.31 \pm 0.49$ & $2.03 \pm 0.49$ & $1.12 \pm 0.24$ \\
\hline+49 & $2.18 \pm 0.31$ & $2.24 \pm 0.36$ & $1.19 \pm 0.19$ \\
\hline
\end{tabular}

${ }^{1} \mathrm{PHA}=$ stimulated with phytohemagglutinin; $\mathrm{ConA}=$ stimulated with concanavalin $\mathrm{A}$; $\mathrm{PWM}=$ stimulated with pokeweed mitogen

a, b columns with different letters differ significantly $(\mathrm{P}<0.01)$

No anti-BTV antibodies were detected in the serum of NVa and NVaT goats, and in the serum of $\mathrm{Va}$ and $\mathrm{VaT}$ goats before vaccination or seven days after. Contrarily, 21 and 49 days after vaccination, BTV specific antibodies were detected in the serum of either Va or VaT goats (Figure 1). 


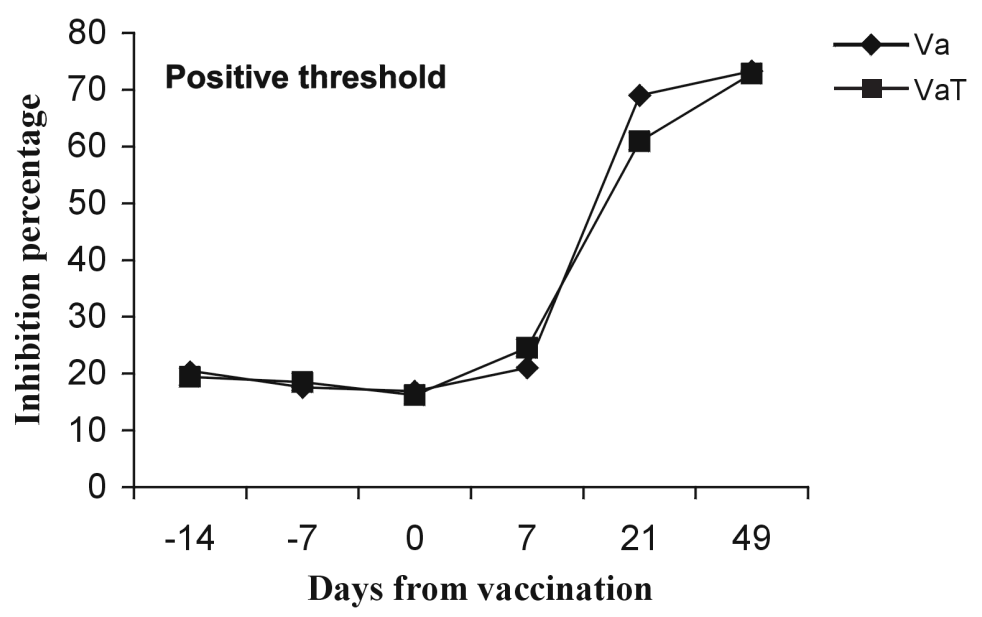

Figure 1. Anti-BTV antibodies in serum of goats vaccinated. An inhibition percentage of $50 \%$ was considered as the positive threshold. Values are expressed as Lsmeans \pm SD. Va: vaccinated; VaT: vaccinated and treated with thuya

\section{DISCUSSION}

The observation that administration of thuya in goats can prevent the impairment of lymphoblastogenesis following vaccination against BTV is novel. However, our results support the hypothesis that homeopathic medications may be of help in alleviating side effects of vaccinations (Teixeira, 2002).

\section{CONCLUSIONS}

Larger studies are encouraged to assess the effects of thuya also in other ruminant species vaccinated against BTV or in other species recognized to be affected by vaccine dependent immunosuppression (Strasser et al., 2003).

\section{REFERENCES}

Lacetera N., Ronchi B., 2004. Nonspecific lymphoblastogenesis of mononuclear cells from goats vaccinated with a live attenuated bluetongue virus vaccine. Amer. J. Vet. Res. (in press)

Schuberth H.-J., Ridel-Caspari G., Leibold W., 2002. Flow cytometric testing of immunological effects of a phytomedicinal combination (EquiMun) and its compounds on bovine leucocytes. J. Vet. Med. A 49, 291-298

Strasser A., May B., Teltscher A., Wistrela E., Niedermüller H., 2003. Immune modulation following immunization with polyvalent vaccines in dogs. Vet. Immunol. Immunopathol. 94, 113-121

Teixeira M.Z., 2002. Is there scientific evidence that suppression of acute diseases in childhood induces chronic diseases in the future. Homeopathy 91, 207-216 